\title{
Clinical features as predictors of histologically confirmed inflammation in patients with lumbar disc herniation with associated radiculopathy
}

\author{
Jon J. Ford ${ }^{1 *}$ D, Omar Kaddour ${ }^{2}$, Michael Gonzales ${ }^{3}$, Patrick Page ${ }^{4}$ and Andrew J. Hahne ${ }^{1}$
}

\begin{abstract}
Background: An understanding of the clinical features of inflammation in low back pain with or without leg symptoms may allow targeted evaluations of anti-inflammatory treatment in randomised-controlled-trials and clinical practice.

Purpose: This study evaluated the diagnostic accuracy of clinical features to predict the presence/absence of histologically confirmed inflammation in herniated disc specimens removed at surgery in patients with lumbar disc herniation and associated radiculopathy (DHR).

Study design: Cohort Study.

Methods: Disc material from patients with DHR undergoing lumbar discectomy was sampled and underwent histological/immunohistochemistry analyses. Control discs were sampled from patients undergoing surgical correction for scoliosis. Baseline assessment comprising sociodemographic factors, subjective examination, physical examination and psychosocial screening was conducted and a range of potential clinical predictors of inflammation developed based on the existing literature. Multi-variate analysis was undertaken to determine diagnostic accuracy.

Results: Forty patients with DHR and three control patients were recruited. None of the control discs had evidence of inflammation compared to $28 \%$ of patients with DHR. Predictors of the presence of histologically confirmed inflammation included back pain $<5 / 10$, symptoms worse the next day after injury, lumbar flexion range between 0 and $30^{\circ}$ and a positive clinical inflammation score (at least 3 of: constant symptoms, morning pain/stiffness greater than 60-min, short walking not easing symptoms and significant night symptoms). The model achieved a sensitivity of $90.9 \%$, a specificity of $92.9 \%$, and a predictive accuracy of $92.3 \%$.
\end{abstract}

Conclusion: In a sample of patients with lumbar DHR a combination of clinical features predicted the presence or absence of histologically confirmed inflammation.

Clinical relevance: These clinical features may enable targeted anti-inflammatory treatment in future RCTs and in clinical practice.

Keywords: Inflammation, Back pain, Clinical predictors, Lumbar disc herniation, Radiculopathy

\footnotetext{
* Correspondence: j.ford@latrobe.edu.au

${ }^{1}$ College of Science, Health \& Engineering, La Trobe University, Bundoora, Victoria 3085, Australia

Full list of author information is available at the end of the article
}

C C The Author(s). 2020 Open Access This article is licensed under a Creative Commons Attribution 4.0 International License, which permits use, sharing, adaptation, distribution and reproduction in any medium or format, as long as you give appropriate credit to the original author(s) and the source, provide a link to the Creative Commons licence, and indicate if changes were made. The images or other third party material in this article are included in the article's Creative Commons licence, unless indicated otherwise in a credit line to the material. If material is not included in the article's Creative Commons licence and your intended use is not permitted by statutory regulation or exceeds the permitted use, you will need to obtain permission directly from the copyright holder. To view a copy of this licence, visit http://creativecommons.org/licenses/by/4.0/. The Creative Commons Public Domain Dedication waiver (http://creativecommons.org/publicdomain/zero/1.0/) applies to the data made available in this article, unless otherwise stated in a credit line to the data. 


\section{What is known about the subject}

- Evidence suggests that inflammatory processes are a potential treatment target for people with LBP.

- There is limited evidence for the effectiveness of anti-inflammatory treatment in LBP.

- A method of detecting patients with LBP and associated inflammation is likely required so their treatment can be tailored appropriately.

\section{What this study adds to existing knowledge}

- A composite clinical inflammation score predicted histological inflammation in discs from patients undergoing lumbar discectomy.

- Control disc specimens had no histological evidence of inflammation.

- These clinical features may enable targeted antiinflammatory treatment in future RCTs and in clinical practice.

\section{Introduction}

Biologically, the degenerated lumbar intervertebral disc is a potential contributor to low back pain with or without leg symptoms (LBP) [4]. The mechanisms resulting in disc related pain are not completely understood, however the role of inflammation in disc degeneration and pain generation is supported by significant evidence [1, 33]. Studies investigating people with LBP have shown pathoanatomical changes in lumbar discs which are not observed in non-painful degenerative discs [32]. Studies have also identified the presence of inflammatory markers in people with painful degenerative discs and disc herniation with associated radiculopathy (DHR) [43] seen histologically in disc tissue [15, 17, 38, 45], using other inflammatory markers in disc tissue $[5,22]$ and measured by serum biomarkers [25]. Furthermore, the high serum tumour necrosis factor in acute LBP was recently demonstrated to be a predictor for poor recovery of pain and activity limitation at 6-months [26].

These findings indicate that inflammatory processes are a plausible treatment target for people with LBP treated in clinical practice or clinical trials. However, there is limited evidence for the effectiveness of anti-inflammatory treatment in LBP including epidural corticosteroid injections [35], non-steroidal anti-inflammatory drugs (NSAIDs) [8, 36, 37] and oral corticosteroids [14, 27, 35] with short term and small effects predominating. RCTs investigating the effectiveness of anti-inflammatory treatments have not selected patients based on the presence of an inflammatory contribution to LBP. In these trials, if a substantial proportion of the sample do not have an inflammatory component to their LBP, then any effect of antiinflammatory treatment on the sample overall has the potential to be diluted. To rectify this problem, a method of detecting patients with LBP and associated inflammation would be required so treatment can be tailored accordingly.

A number of credible studies have validated clinical features of inflammatory back pain (IBP) particularly for spondyloarthropathy $[2,24,39,42]$ which include age < 40 years, insidious onset, morning stiffness, improvement with exercise, no improvement with rest and pain at night with improvement upon getting up from bed [49]. However, IBP involves different mechanisms and is therefore likely to be a different condition in comparison to disc related LBP with an inflammatory contribution. There is some data on clinical features of disc related LBP and associated inflammation, however no studies have investigated the diagnostic accuracy of clinical features in predicting the presence of confirmed inflammation $[38,45]$.

An understanding of the clinical features of inflammation in LBP has the potential to allow more targeted treatment clinically and more precise evaluations of anti-inflammatory effectiveness in RCTs. Therefore, this prospective study aimed to evaluate the diagnostic accuracy of clinical features to predict the presence/absence of histologically confirmed inflammation in herniated disc specimens removed at surgery in patients with DHR. As part of this aim the presence of histologically confirmed inflammation in herniated disc tissue was compared to control disc specimens from patients having surgical correction for scoliosis. Our hypothesis is that a multi-variate model based on clinical features would demonstrate high levels of sensitivity and specificity in predicting histologically confirmed inflammation.

\section{Materials and methods Study population}

Ethics approval for the study was obtained from The University of Melbourne and relevant hospital ethics committees. Eleven orthopedic surgeons and neurosurgeons from Epworth Healthcare Richmond, Melbourne Health and Freemasons Hospitals in Victoria, Australia participated in the study. Patients were consecutively identified from those booked for surgical correction of scoliosis or lumbar discectomy and verbal/written informed consent was obtained.

Patients were eligible if they were literate in spoken and written English, had undergone magnetic resonance imaging (MRI) of the lumbar spine in the past 6-months, were booked in for lumbar discectomy or surgical correction of scoliosis and were willing to donate disc tissue specimens removed during surgery. Patients were excluded if they had computerized tomography scan or MRI confirmed central or lateral canal stenosis, spondylolisthesis/spondylosis or symptoms due to non-mechanical pathology (e.g. tumour, 
infection, inflammatory arthritis) or previous surgery to the lumbar spine. Control patients were excluded if they had received treatment for LBP in the previous 12-months due to the potential risk of having inflammatory markers in their disc tissue.

\section{Tissue collecting procedure}

The study surgeons had an average of 10-years' experience in spinal surgery in major private and public teaching hospitals in Australia /overseas and regularly performed discectomy and/or scoliosis correction as part of their clinical practice.

Discectomy was performed with patients in prone. A 19-gauge needle was placed into the spinous process of the disc to be operated on and the level checked with the image intensifier. An incision was made over the spinous process approximately $2-3 \mathrm{~cm}$ in length and a standard unilateral retractor used. A variable amount of lamina and facet joint was removed together with the ligamentum flavum to gain access. The nerve root was retracted and the disc annulus incised with a number 11 blade and the herniated material removed with a pituitary rongeur. As much herniated disc tissue as possible was collected from each patient with a particular focus around the nerve root where inflammation is likely to predominate. Sequestered disc material was not sampled. Specimens with formalin were placed in a coded container to de-identify the patient, then transported to the Department of Anatomical Pathology at The Royal Melbourne Hospital (Melbourne, Australia) for histological and immune-histochemical analyses.

\section{Histological analysis}

Specimens were fixed in formalin for a minimum of 24$\mathrm{h}$ and then routinely processed for liquid paraffin embedding at a temperature of $58^{\circ} \mathrm{C}$. Preparation for paraffin embedding was conducted by first dehydrating the tissue progressively in graded alcohols of 60, 65, 95, 95 and $100 \%$ alcohol. Three serial sections of $3 \mu \mathrm{m}$ thickness was subsequently cut from paraffin blocks.

The sections of herniated and control disc tissue were stained with haematoxylin and eosin and examined under the microscope in $\times 200$ magnification medium power fields. Only sections displaying evidence of inflammation as depicted in the histological stain underwent immunohistochemistry analysis [7]. The first five specimens underwent both histological and immunohistochemistry analysis and there were no cases where the two test results were discordant for presence of inflammatory markers.

\section{Immunohistochemistry analysis}

Specimens with evidence of inflammation from the histological stain were analysed using standard immunohistochemistry protocols for the presence of inflammatory cells. Macrophages, B lymphocytes and $\mathrm{T}$ lymphocytes were identified as CD68, CD20 and CD3 positive cells respectively using $\mathrm{DAKO}^{1}$ inflammatory cell antibodies. Specimens were heated at $100^{\circ} \mathrm{C}$ for 20 -min in a citrate buffer $(\mathrm{pH} 6)$ as part of the heat induced antigen retrieval process on board a Vision Bio systems Bond-Max Immunostainer. ${ }^{2}$ The primary antibodies were then applied at the appropriate dilutions for 25-min at room temperature. The slide was rinsed again in phosphate buffered saline (PBS) for 5-min. The secondary antibody, consisting of $200 \mu \mathrm{l}$ of Envision ${ }^{3}$ and $200 \mu \mathrm{l}$ of Envision ${ }^{4}$ was added using the DAKO Autostainer. ${ }^{5}$

The slide was incubated at room temperature for 30min and peroxidase added using a Labelled Polymer Immunoperoxidase System (DAKO catalogue number DS9713) according to the manufacturer's instructions. The slide was again rinsed in PBS before peroxidase activity could be demonstrated by applying 3, 3Diaminobenzidine (DAKO catalogue number Bond$\mathrm{DAB}$ ) for 10 -min. The slide was washed using tap water and counterstained in Lillee-Mayer Haemotoxylin ${ }^{6}$ (blue nuclear staining). The slide was then finally washed with tap water, dehydrated in ethanol and cleared in xylene before visualisation under the microscope.

Semi-quantitative estimates of cell counts were made in $\times 200$ magnification medium power fields. Tissue specimens were classified as having $0=$ no cells; $1=\mathrm{a}$ few cells; $2=$ moderate cells or $3=$ abundant cells [7] . Using the labelled polymer immune-peroxidase method, a brown cellular stain indicated a positive stain for an inflammatory cell. On the assumption that inflammatory sites might be variably located within the disc tissue, the slide demonstrating the most evidence of inflammation granulation infiltrate was selected from which cellular evidence of inflammation would be determined. Histologically confirmed inflammation was defined as at least moderate cells of any type in a specimen. Cell counts were done by an independent anatomical pathologist with 23-years of specialist experience. The pathologist was blinded to any clinical or demographic information on the origin of the disc material.

\section{Potential clinical features of inflammation}

All patients having discectomy underwent a comprehensive and standardised assessment prior to their surgery upon admission to hospital blinded to any tests regarding histologically confirmed inflammation. Clinical

\footnotetext{
${ }^{1}$ DAKO, Copenhagen, Denmark

${ }^{2}$ Vision Biosystems, Melbourne, Australia

${ }^{3} \mathrm{DAKO}$, Copenhagen, Denmark

${ }^{4}$ DAKO, Copenhagen, Denmark

${ }^{5}$ DAKO, Copenhagen, Denmark

${ }^{6}$ DAKO, Copenhagen, Denmark
} 
assessment items included sociodemographic factors, low back pain-related subjective examination (measuring symptom duration, location and nature of symptoms, pain drawing, aggravating and easing factors, and history of symptoms) [10], low back pain-related physical examination (measuring active movement testing, straight leg raise, crossed straight leg raise, provocative sacro-iliac joint testing, lower limb neurological examination, response to mechanical loading strategies and lumbar palpation) and psychosocial risk factors comprising the Örebro Musculoskeletal Pain Questionnaire [28] and non-organic signs [47]. The clinical assessment had acceptable evidence of reliability and validity $[3,10,12,16,19,50]$.

Self-administered standardized outcome measures were completed comprising valid and reliable measures of activity limitation (Oswestry Disability Index) [13, 31] and a series of visual analogue scales [23, 29] as a measure of overall symptoms, back symptoms and leg symptoms.

Magnetic resonance imaging (MRI) scans were reported by a study radiologist, blinded to the baseline clinical assessment/patient outcomes, who assessed the patient's MRI scan using a reliable and valid protocol [9, 34].

Based on previous diagnostic accuracy studies in LBP $[20,40,44]$, clinical features are more likely to be predictive when multiple features are combined into a composite score. Research suggests that certain subjective examination items (age at onset $<40$ years, insidious onset, improvement with exercise, no improvement with rest and pain at night associated with improvement upon getting out of bed) are indicative of IBP in people with spondyloarthropathy [49]. However, the mechanisms underpinning IBP are substantially different to LBP with an inflammatory component due to DHR. As such the clinical features for IBP were modified for the selected sample based on expert opinion [21,48] and evidence of prognostic ability [11] to form a composite clinical inflammation score as a potential predictor. A positive on this score was at least three of: constant symptoms, morning pain/stiffness greater than 60-min, short walking not easing symptoms and significant night symptoms (waking most/every night, plus waking is not due to movement in bed and/or unable to return to sleep without sitting up, getting out of bed or taking medication).

Potential predictors evaluated therefore included all items from the clinical assessment, outcome measures, MRI scans and the composite clinical inflammation score.

\section{Statistical analysis}

All potential predictors of histologically confirmed inflammation were assessed for multicollinearity, which was considered likely if correlations between factors were $>0.8$ [6]. For univariate analysis, each potential predictor was tested for its association with histologically confirmed inflammation via chi-square testing (Fisher's Exact test when cell values less than five were present), Spearman's rank order correlation, or Pearson's correlation for nominal, ordinal and continuous data respectively. Significant univariate predictors $(p<0.05)$ then progressed to multivariate logistic regression analysis. To avoid overfitting models with our relatively small sample size, we applied a maximum limit of 8 factors to progress to multivariate analysis based on the guideline of one factor for every five to ten patients [46]. In the multivariate stage, a Wald backwards stepwise approach was utilised. It was planned to report the multivariate model containing all significant univariate predictors (Model 1), the final model containing only independently significant predictors after backward deletion (Model 2), and a third model displaying the best balance of parsimony and performance (e.g. highest sensitivity and specificity with the fewest predictors). All analyses were undertaken using SPSS 22 and Microsoft Excel.

\section{Results}

Histology was undertaken on the disc tissue of 43 patients. Three of these patients (all negative for inflammation) had no baseline data available so they were excluded from the study. The clinical characteristics of the final sample $(n=40)$ are outlined in Table 1. All herniated disc specimens were from lower lumbar discs (L3/4 to L5/S1). Three female control patients, aged 16, 18 and 28-years provided a specimen from a single lower lumbar disc (L3/4 to L5/S1).

Of the 40 DHR patients in the study, 11 (28\%) had at least moderate histological evidence of inflammation and were scored as positive for inflammation. All of these specimens demonstrated typical haematoxylin and eosin stained features of granulation tissue, which was predominately composed of infiltrating large mononuclear cells (Fig. 1). Immunohistochemical staining with monoclonal antibodies showed moderate to abundant infiltration of CD68-positive macrophages in all specimens (Fig. 2). In contrast, CD3-positive $\mathrm{T}$ lymphocytes and CD20-positive $\mathrm{B}$ lymphocytes were not detected in abundance, demonstrating few to moderate cell counts. The relative prevalence of inflammatory cells for each of the specimens is displayed in Fig. 3.

Hematoxylin and eosin staining of control disc tissue revealed no evidence of infiltration of inflammatory granulation tissue (Fig. 1).

\section{Clinical features predicting histologically confirmed inflammation}

On univariate analysis, six clinical features showed a statistically significant association with histologically confirmed inflammation (Additional file 1). Additional files 2 
Table 1 Clinical characteristics of patients $(n=40)$

\begin{tabular}{|c|c|}
\hline Characteristic & Mean (SD) or $\mathrm{N}(\%)$ \\
\hline Age (years) & $43.5(14.7)$ \\
\hline Gender (Male) & $31(77.5 \%)$ \\
\hline Smoker & $8(20.0 \%)$ \\
\hline Compensation claim & $10(25.0 \%)$ \\
\hline Back pain (VAS /10) & $5.3(2.1)$ \\
\hline Leg pain (VAS /10) & $6.3(2.3)$ \\
\hline Pain or paraesthesia below knee & 37 (92.5\%) \\
\hline First episode & $17(42.5 \%)$ \\
\hline \multicolumn{2}{|l|}{ Duration of symptoms (current episode) } \\
\hline 1 week - 1 month & $8(20.0 \%)$ \\
\hline $2-3$ months & $8(20.0 \%)$ \\
\hline $4-6$ months & $13(32.5 \%)$ \\
\hline 7-12 months & $2(5.0 \%)$ \\
\hline$>12$ months & $9(22.5 \%)$ \\
\hline Activity limitation (Oswestry) & $40.1(15.8)$ \\
\hline Örebro score & $115.7(22.8)$ \\
\hline \multicolumn{2}{|l|}{ MRI findings } \\
\hline \multicolumn{2}{|l|}{ Herniation type } \\
\hline Bulge or normal & $1(2.5 \%)$ \\
\hline Protrusion & $16(40.0 \%)$ \\
\hline Extrusion & $21(52.5 \%)$ \\
\hline Sequestration & $1(2.5 \%)$ \\
\hline \multicolumn{2}{|l|}{ Nerve root involvement } \\
\hline None & $0(0.0 \%)$ \\
\hline Contact & $2(5.0 \%)$ \\
\hline Displacement & $6(15 \%)$ \\
\hline Compression & $31(77.5 \%)$ \\
\hline \multicolumn{2}{|l|}{ Annular tear } \\
\hline None & $4(10.3 \%)$ \\
\hline Mild tear & $23(59.0 \%)$ \\
\hline Severe tear & $12(30.8 \%)$ \\
\hline \multicolumn{2}{|l|}{ Physical examination findings: } \\
\hline Ipsilateral SLR: mean (SD) degrees & $50.2(17.8)$ \\
\hline Contralateral SLR: mean (SD) degrees & $69.5(15.8)$ \\
\hline \multicolumn{2}{|l|}{ Neurological deficit (affected side) } \\
\hline Reflex deficit & $28(70.0 \%)$ \\
\hline Myotomal deficit & $16(40.0 \%)$ \\
\hline Dermatomal deficit & 31 (77.5\%) \\
\hline At least one neurological deficit & $38(95.0 \%)$ \\
\hline
\end{tabular}

SD Standard deviation, $N$ Number of patients, \% Percentage, VAS Visual analogue scale, SLR Straight Leg Raise, MRI Magnetic resonance imaging, Örebro Örebro Musculoskeletal Pain Questionnaire

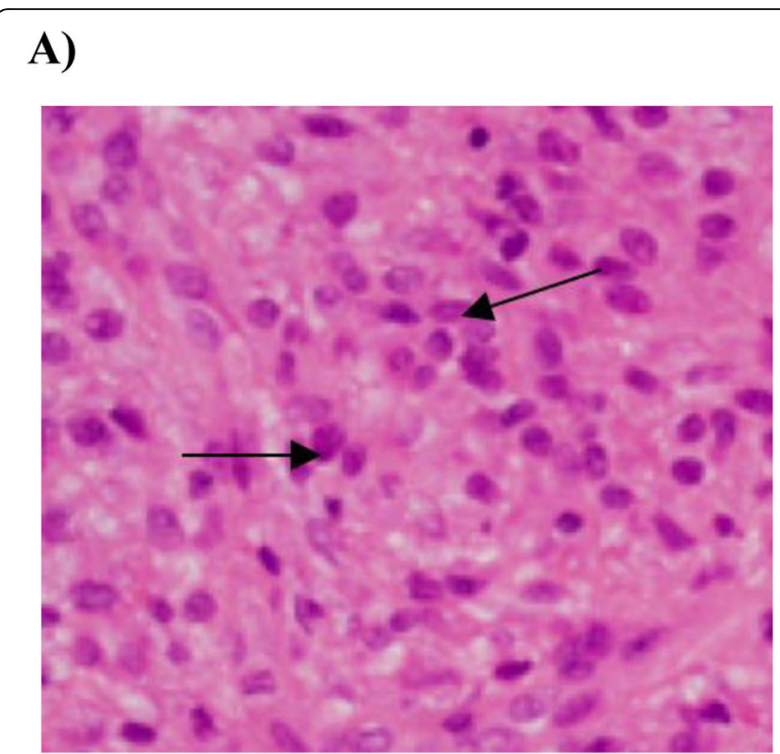

\section{B)}

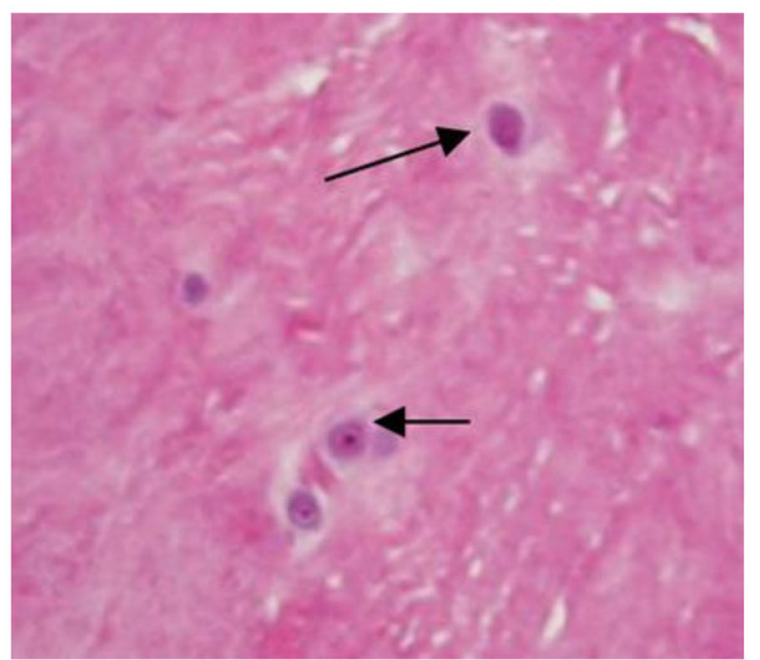

Fig. 1 Hematoxylin and eosin stained sections. Original magnification $\times 200$. Herniated disc sample showing inflammatory granulation tissue infiltration (a), Control disc sample showing chondrocyte nuclei and no evidence of inflammatory cell infiltration (b)

and 3 provide the results for all univariate features analysed. Back pain $<5 / 10$ was the variable with the best individual predictive value for histologically confirmed inflammation, with a sensitivity of $72.7 \%$, a specificity of $82.8 \%$, and correct prediction of the presence or absence of inflammation in $80.0 \%$ of patients. The six significant features on univariate analysis progressed to multivariate logistic regression analysis to develop clinical models predictive of histologically confirmed inflammation.

Tables 2 and 3 show the multivariate models. After Wald backward elimination of the six significant univariate features, two features remained as significant independent predictors of inflammation in the final model (clinical 
A)

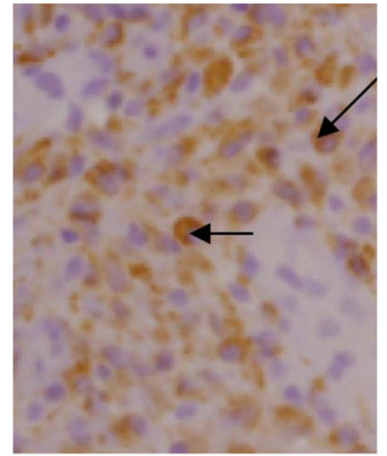

B)

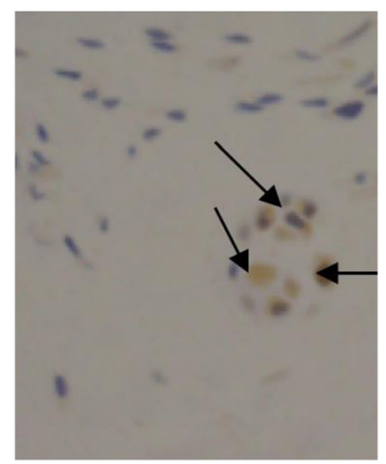

C)

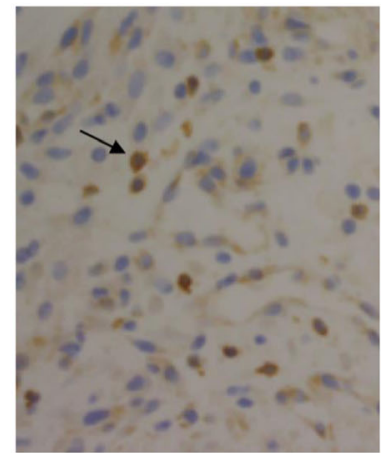

Fig. 2 Immunohistochemical staining of herniated disc tissue sections with inflammatory cells brown with a blue nucleus. Original magnification $x$ 200. CD68-positive macrophages ( 3 = abundant) (a), CD20-positive T lymphocytes ( $1=$ a few cells) (b), CD3-positive B lymphocytes ( $1=$ a few cells) $(C)$

inflammation score of 3 or more, and back pain $<5 / 10$ on the VAS). A model containing four features was found to have the best balance of performance and parsimony. This model achieved a sensitivity of $90.9 \%$, a specificity of $92.9 \%$ and predictive accuracy of $92.3 \%$ for the presence or absence of inflammation, with positive and negative likelihood ratios of 12.7 and 0.1 respectively (Table 3$)$.

\section{Discussion}

This results of this study show that the combined clinical features of back pain $<5 / 10$, symptoms being worse the next day after injury, a lumbar flexion range of motion between 0 and $30^{\circ}$ and the composite inflammation score (at least 3 of constant symptoms, morning pain/ stiffness greater than 60 -min, short walking not easing

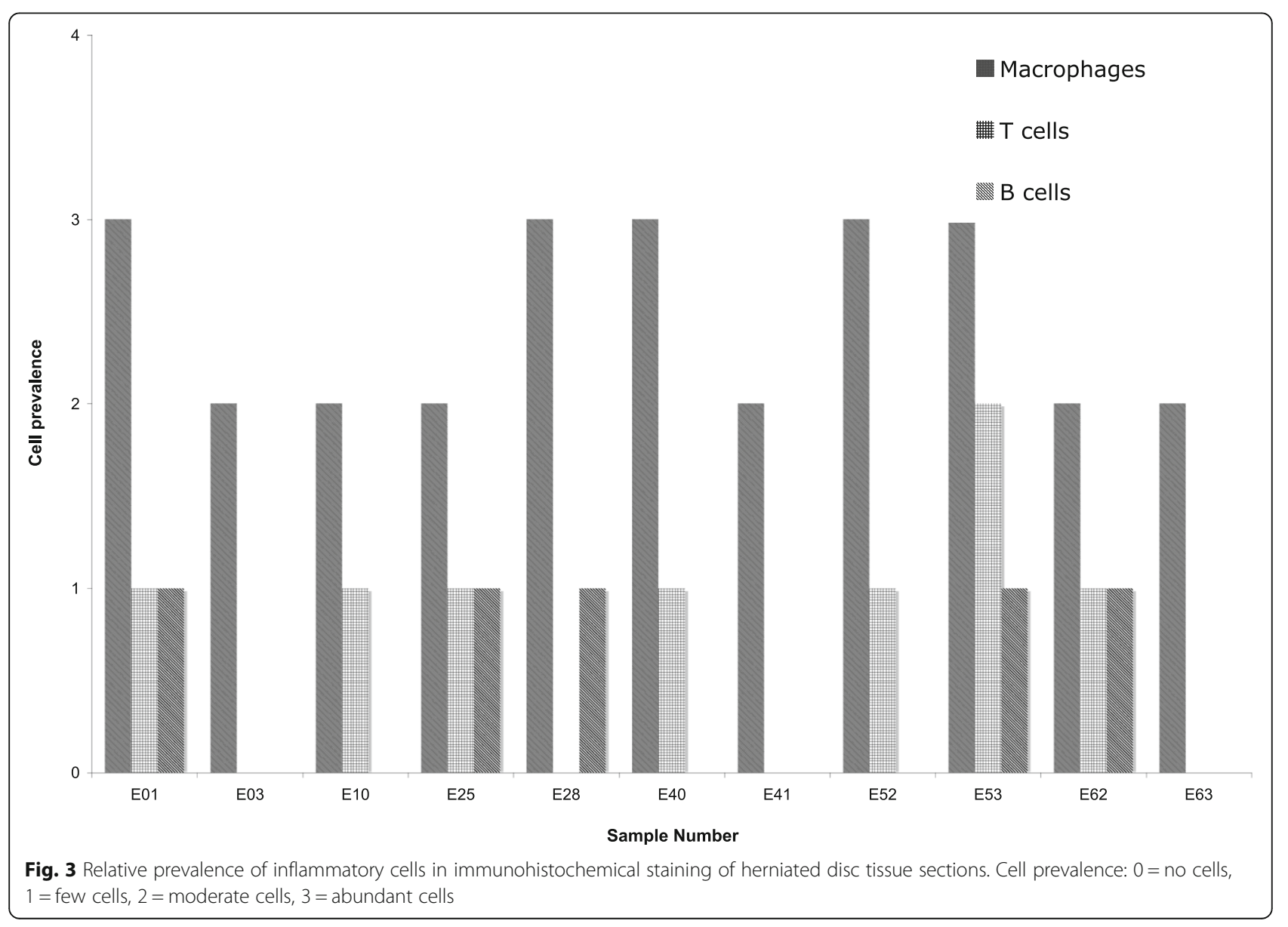


Table 2 Multivariate models for predicting histologically confirmed inflammation

\begin{tabular}{|c|c|c|c|c|c|}
\hline & B (intercept) & $p$-value & Exp(B) (odds ratio) & Lower 95\%Cl for $\operatorname{Exp}(\mathrm{B})$ & Upper $95 \% \mathrm{Cl}$ for $\operatorname{Exp}(\mathrm{B})$ \\
\hline \multicolumn{6}{|c|}{ Model 1: (all significant univariate factors included) } \\
\hline Clinical inflammation score $>/=3$ & 2.7 & 0.05 & 15.2 & 1.0 & 233.6 \\
\hline Back pain $<5 / 10$ & 2.2 & 0.19 & 9.1 & 0.3 & 258.0 \\
\hline Can sit with a firm backrest $>30$ min & 0.2 & 0.90 & 1.2 & 0.1 & 24.3 \\
\hline Worse the next day after injury & 1.2 & 0.35 & 3.2 & 0.3 & 36.2 \\
\hline Flexion range of motion $0-30^{\circ}$ & 1.1 & 0.37 & 3.1 & 0.3 & 38.2 \\
\hline MRI - disc extrusion & 1.0 & 0.47 & 2.7 & 0.2 & 40.4 \\
\hline Intercept & -4.9 & 0.00 & 0.0 & & \\
\hline \multicolumn{6}{|c|}{ Model 2: (Final model with only significant predictors remaining) } \\
\hline Clinical inflammation score $>/=3$ & 2.8 & 0.03 & 16.5 & 1.4 & 195.3 \\
\hline Back pain $<5 / 10$ & 3.1 & 0.01 & 23.1 & 2.4 & 224.6 \\
\hline Constant & -3.1 & 0.00 & 0.0 & & \\
\hline \multicolumn{6}{|c|}{ Model 3: Best balance of model parsimony and performance } \\
\hline Clinical inflammation score $>/=3$ & 2.6 & 0.04 & 12.8 & 1.1 & 154.7 \\
\hline Back pain $<5 / 10$ & 2.8 & 0.02 & 16.4 & 1.6 & 172.7 \\
\hline Worse the next day after injury & 1.4 & 0.25 & 3.9 & 0.4 & 39.2 \\
\hline Flexion range of motion $0-30^{\circ}$ & 1.4 & 0.24 & 4.0 & 0.4 & 40.9 \\
\hline Constant & -4.8 & 0.00 & 0.0 & & \\
\hline
\end{tabular}

$B$ Coefficient for the constant (intercept), $\operatorname{Exp}(B)$ Odds ratio, $C l$ Confidence interval for the odds ratio, MRI Magnetic resonance imaging, Constant Constant symptoms

symptoms and significant night symptoms) predicted the presence or absence of histologically confirmed inflammation in disc specimens removed from patients undergoing surgical discectomy for DHR. The validity of these findings was strengthened by the fact that there was no histological evidence of inflammation in three control specimens from three patients with no current or recent LBP. This appears to be the first study to evaluate the diagnostic accuracy of clinical features in predicting histological or other markers of inflammation in patients with lumbar DHR. Identifying clinical features of inflammation in LBP has the potential of allowing more targeted anti-inflammatory treatment in future RCTs and in clinical practice.
The data show high levels of diagnostic accuracy when compared with other tests evaluated in the LBP literature to date. Systematic reviews on patients with zygapophyseal joint dysfunction [30], lumbar radiculopathy [41] and serious pathologies causing back pain [44] show limited diagnostic accuracy of clinical features. There is some evidence of diagnostic accuracy [20] for a combination of clinical tests in sacro-iliac joint dysfunction (positive likelihood ratio of 3.2); and centralisation for discogenic pain (positive likelihood ratio of 2.8) however these parameters are lower than those reported in our study, particularly for our models combining multiple clinical features. Several of the predictive clinical features are consistent with those accepted as indicative of

Table 3 Performance of multivariate models for predicting histologically confirmed inflammation

\begin{tabular}{|c|c|c|c|c|c|c|c|c|c|c|c|c|}
\hline \multirow[b]{2}{*}{ Model } & \multirow[b]{2}{*}{$\mathrm{N}$} & \multicolumn{2}{|c|}{$\begin{array}{l}\text { Histology negative for } \\
\text { inflammation }\end{array}$} & \multicolumn{2}{|c|}{$\begin{array}{l}\text { Histology positive for } \\
\text { inflammation }\end{array}$} & \multirow[b]{2}{*}{ Sensitivity } & \multirow[b]{2}{*}{ Specificity } & \multirow[b]{2}{*}{$\begin{array}{l}\% \\
\text { correctly } \\
\text { predicted }\end{array}$} & \multirow[b]{2}{*}{ LR+ } & \multirow[b]{2}{*}{ LR- } & \multirow[b]{2}{*}{$\begin{array}{l}\text { Diagnostic } \\
\text { Odds Ratio }\end{array}$} & \multirow[b]{2}{*}{$\begin{array}{l}\text { R-square } \\
\text { (Cox \& } \\
\text { Snell) }\end{array}$} \\
\hline & & $\begin{array}{l}\text { Predicted } \\
\text { negative for } \\
\text { inflammation }\end{array}$ & $\begin{array}{l}\text { Predicted } \\
\text { positive for } \\
\text { inflammation }\end{array}$ & $\begin{array}{l}\text { Predicted } \\
\text { negative for } \\
\text { inflammation }\end{array}$ & $\begin{array}{l}\text { Predicted } \\
\text { positive for } \\
\text { inflammation }\end{array}$ & & & & & & & \\
\hline $\begin{array}{l}\text { Model } \\
1\end{array}$ & 37 & 24 & 2 & 1 & 10 & $90.9 \%$ & $92.3 \%$ & $91.9 \%$ & 11.8 & 0.1 & 120.0 & 0.42 \\
\hline $\begin{array}{l}\text { Model } \\
2\end{array}$ & 40 & 24 & 5 & 3 & 8 & $72.7 \%$ & $82.8 \%$ & $80.0 \%$ & 4.2 & 0.3 & 12.8 & 0.36 \\
\hline $\begin{array}{l}\text { Model } \\
3\end{array}$ & 39 & 26 & 2 & 1 & 10 & $90.9 \%$ & $92.9 \%$ & $92.3 \%$ & 12.7 & 0.1 & 130.0 & 0.42 \\
\hline
\end{tabular}

$N$ Number of samples, \% Percentage, $L R+$ Positive likelihood ratio, $L R$ - Negative likelihood ratio, $R$-square Coefficient of determination - the proportion of variance in the presence or absence of inflammation in the disc that is explained by the predictive model 
inflammatory processes in patients with spondyloarthropathy $[2,24,39,42]$ despite the putative mechanisms being different to LBP and DHR. They are also consistent with an expert panel study on the clinical features of LBP in association with inflammation and in the absence of IBP [48].

\section{Limitations}

This study had a relatively small sample size and further validation of the multivariate model on a larger sample size is required. The identified clinical features are only applicable to people with DHR limiting generalisability. However, it is plausible that the mechanisms underpinning these clinical features could also apply to other types of LBP and potentially other musculoskeletal conditions. The method of deriving the composite clinical inflammation score has not been previously validated but is consistent with other clinical tests for LBP where combinations of tests are considered more likely to be informative than single tests alone [20, 40, 44]. The composite score was also derived from the literature on IBP, clinical experts in the area of LBP [48] and evidence of prognostic ability [11]. Only three relatively young female control patients were tested for histological evidence of inflammation due to feasibility issues in obtaining age matched subjects however the negative results in these asymptomatic cases are consistent with data from other studies $[15,18,45]$.

\section{Conclusion}

This study involving patients with lumbar disc herniation and associated radiculopathy showed that a combination of clinical features predicted the presence or absence of histologically confirmed inflammation. Further research is required to externally validate these findings in different types of LBP and other musculoskeletal conditions. The identified clinical features of inflammation have the potential to allow targeted anti-inflammatory treatment in future RCTs and in clinical practice.

\section{Supplementary information}

Supplementary information accompanies this paper at https://doi.org/10. 1186/s12891-020-03590-x.

Additional file 1. All significant univariate predictors of histologically confirmed inflammation

Additional file 2. Univariate analysis of dichotomous variables for predicting histologically confirmed inflammation.

Additional file 3. Univariate analysis of ordinal, continuous, and multinominal variables for predicting histologically confirmed inflammation.

\section{Abbreviations}

DHR: Disc herniation and associated radiculopathy; RCT: Randomised controlled trail; LBP: Low back pain; NSAID: Non-steroidal anti-inflammatory drugs; IBP: Inflammatory back pain; MRI: Magnetic resonance imaging; PBS: Phosphate buffered saline; VAS: Visual analogue scale; SLR: Straight leg raise; N: Number of samples; LR+: Likelihood ratio positive; LR-: Likelihood ratio negative

\section{Acknowledgements}

The authors would like to thank Dr. Arun Prasad Balasundaram for providing technical support in the preparation of the manuscript.

\section{Authors' contributions}

JF and AH had full access to all of the data in the study and take responsibility for the integrity of the data and the accuracy of the data analysis. Literature search (JF, AH, OK). Study conception (JF and AH assisted by OK and MG). Study design (JF and AH assisted by OK and MG). Statistical analysis strategy (AH and JF). Schedule preparation (JF). Securing funding (JF). Project manager (JF). Data collection (OK, JF, AH, MG, PP). Data analysis $(\mathrm{AH}, \mathrm{JF}, \mathrm{OK})$. Data interpretation (JF and $\mathrm{AH}$ assisted by all co-authors). Manuscript preparation (JF assisted by all co-authors). The author(s) read and approved the final manuscript.

\section{Funding}

This study did not receive funding from any source. Practitioners collecting and analysing the data did so at no charge.

\section{Availability of data and materials}

The data generated and//or analysed during the current study are not publicly available but are available from the corresponding author on reasonable request.

\section{Ethics approval and consent to participate}

The methodology of the current study was performed in accordance with the requirements of The University of Melbourne Human Research Ethics Committee, The Epworth Hospital Ethics Committee and the Melbourne Health Research Ethics Committee. This study was registered as HREC No. 040634.

Verbal/written informed consent was obtained from patients.

Consent for publication

Verbal/written consent for publication was obtained from patients.

\section{Competing interests}

The authors declare that they have no competing interests.

\section{Author details}

${ }^{1}$ College of Science, Health \& Engineering, La Trobe University, Bundoora, Victoria 3085, Australia. ${ }^{2}$ Back in Form Physiotherapy, Ascot Vale, Victoria, Australia. ${ }^{3}$ The Royal Melbourne Hospital, Parkville, Victoria, Australia. ${ }^{4}$ Box Hill Radiology, Epworth Eastern Hospital, Box Hill, Victoria, Australia.

Received: 5 March 2020 Accepted: 13 August 2020

Published online: 21 August 2020

References

1. Adams MA, Stefanakis M, Dolan P. Healing of a painful intervertebral disc should not be confused with reversing disc degeneration: implications for physical therapies for discogenic back pain. Clin Biomech. 2010;25(10):96171.

2. Adizie T, Elamanchi S, Prabu A, et al. Knowledge of features of inflammatory back pain in primary care in the west midlands: a cross-sectional survey in the United Kingdom. Rheumatol Int. 2018;38(10):1859-63.

3. Apeldoorn AT, Bosselaar $\mathrm{H}$, Ostelo RW, et al. Identification of patients with chronic low back pain who might benefit from additional psychological assessment. Clin J Pain. 2012;28(1):23-31.

4. Bogduk N. Clinical and radiological anatomy of the lumbar spine. 5th ed. New York: Churchill Livingstone; 2012.

5. Burke J, Watson R, McCormack D, et al. Intervertebral discs which cause low back pain secrete high levels of proinflammatory mediators. J Bone Joint Surg. 2002;84B(2):196-201.

6. Campbell P, Bishop A, Dunn KM, et al. Conceptual overlap of psychological constructs in low back pain. Pain. 2013;154(9):1783-91.

7. Doita M, Kanatani T, Harada T, Mizuno K. Immunohistologic study of the ruptured intervertebral disc of the lumbar spine. Spine (Phila Pa 1976). 1996; 21(2):235-41. 
8. Enthoven WT, Roelofs PD, Deyo RA, van Tulder MW, Koes BW. Non-steroidal anti-inflammatory drugs for chronic low back pain. Cochrane Database Syst Rev. 2016;2:CD012087.

9. Fardon D, Milette P. Nomenclature and classification of lumbar disc pathology: recommendations of the combined task forces of the North American Spine Society, American Society of Spine Radiology, and American Society of Neuroradiology. Spine. 2001;26(5):E93-E113.

10. Ford J, Story I, McMeeken J. The test retest reliability and concurrent validity of the subjective complaints questionnaire for low back pain. Man Ther. 2009;14:283-91.

11. Ford JJ, Richards MC, Surkitt LD, et al. Development of a Multivariate Prognostic Model for Pain and Activity Limitation in People With Low Back Disorders Receiving Physiotherapy. Arch Phys Med Rehabil. 2018;99(12): 2504-2512.e12.

12. Ford JJ, Thompson SL, Hahne AJ. A classification and treatment protocol for low back disorders. Part 1: specific manual therapy. Phys Ther Rev. 2011; 16(3):168-77.

13. Frost H, Lamb SE, Stewart-Brown S. Responsiveness of a patient specific outcome measure compared with the Oswestry disability index v2.1 and Roland and Morris disability questionnaire for patients with subacute and chronic low back pain. Spine. 2008;33(22):2450-7.

14. Goldberg H, Firtch W, Tyburski M, et al. Oral Steroids for Acute Radiculopathy Due to a Herniated Lumbar Disk. JAMA. 2015;313(19):191523.

15. Gronblad M, Virri J, Tolonen J, et al. A controlled immunohistochemical study of inflammatory cells in disc herniation tissue. Spine. 1994;19:2744-51.

16. Grotle M, Vollestad N, Brox J. Screening for yellow flags in first-time acute low back pain: reliability and validity of a Norwegian version of the acute low back pain screening questionnaire. Clin J Pain. 2006;22:458-67.

17. Habtemariam A, Gronglad M, Virri J, Seitsala S, Karaharju E. A comparative immunohistochemical study of inflammatory cells in acute-stage and chronic-stage disc herniations. Spine. 1998;23:2159-66.

18. Habtemariam A, Gronglad M, Virri J, et al. Immunocytochemical localization of immunoglobulins in disc herniations. Spine. 1996;21:1864-9.

19. Hahne AJ, Ford JJ, Surkitt LD, et al. Specific treatment of problems of the spine (STOPS): design of a randomised controlled trial comparing specific physiotherapy versus advice for people with subacute low back disorders. BMC Musculoskelet Disord. 2011;12:104.

20. Hancock M, Maher C, Latimer J, et al. Systematic review of tests to identify the disc, SIJ or facet joint as the source of low back pain. Eur Spine J. 2007; 16:1539-50

21. Hengeveld E, Banks K. Maitland's Vertebral Manipulation. Management of Neuromusculoskeletal Disorders. 8th ed. Edinburgh: Churchill Livingstone Elsevier; 2014

22. Jimbo K, Park JS, Yokosuka K, Sato K, Nagata K. Positive feedback loop of interleukin-1 beta upregulating production of inflammatory mediators in human intervertebral disc cells in vitro. J Neurosurg Spine. 2005;2(5):589-95.

23. Joos E, Peretz A, Beguin S, Famaey J. Reliability and reproducibility of visual analogue scale and numeric rating scale for therapeutic evaluation of pain in rheumatic patients. J Rheumatol. 1991;18(8):1269-70.

24. Keeling SO, Majumdar SR, Conner-Spady B, et al. Preliminary validation of a self-reported screening questionnaire for inflammatory back pain. J Rheumatol. 2012;39(4):822-9.

25. Khan AN, Jacobsen HE, Khan J, et al. Inflammatory biomarkers of low back pain and disc degeneration: a review. Ann N Y Acad Sci. 2017;1410(1):68-84.

26. Klyne DM, Barbe MF, van den Hoorn W, Hodges PW. ISSLS PRIZE IN CLINIC AL SCIENCE 2018: Iongitudinal analysis of inflammatory, psychological, and sleep-related factors following an acute low back pain episode-the good, the bad, and the ugly. Eur Spine J. 2018;27(4):763-77.

27. Ko S, Kim S, Kim J, Oh T. The effectiveness of Oral corticosteroids for Management of Lumbar Radiating Pain: randomized, Controlled Trial Study. Clin Orthop Surg. 2016;8(3):262-7.

28. Linton S, Hallden K. Can we screen for problematic back pain? A screening questionnaire for predicting outcome in acute and subacute back pain. Clin J Pain. 1998;14(3):209-15.

29. Love A, Leboeuf C, Crisp T. Chiropractic chronic low back pain sufferers and self-report assessment methods. Part I. a reliability study of the visual analogue scale, the pain drawing and the McGill pain questionnaire. J Manip Physiol Ther. 1989;12(1):21-5.
30. Maas ET, Juch JN, Ostelo RW, et al. Systematic review of patient history and physical examination to diagnose chronic low back pain originating from the facet joints. Eur J Pain. 2017;21(3):403-14.

31. Ostelo RW, de Vet HC. Clinically important outcomes in low back pain. Best Pract Res Clin Rheumatol. 2005;19(4):593-607.

32. Peng B, Hao J, Hou S, Wu W, Jiang D, Fu X, Yang Y. Possible pathogenesis of painful intervertebral disc degeneration. Spine. 2006;31:560-6.

33. Peng BG. Pathophysiology, diagnosis, and treatment of discogenic low back pain. World J Orthp. 2013;4(2):42-52.

34. Pfirrmann C, Dora C, Schmid M, et al. MR image-based grading of lumbar nerve root compromise due to disk herniation: reliability study with surgical correlation. Radiology. 2004;230(2):583-8.

35. Pinto RZ, Maher CG, Ferreira ML, et al. Epidural corticosteroid injections in the management of sciatica: a systematic review and meta-analysis. Ann Intern Med. 2012;157(12):865-77.

36. Rasmussen-Barr E, Held U, Grooten WJ, et al. Non-steroidal antiinflammatory drugs for sciatica. Cochrane Database Syst Rev. 2016;10: Cd012382.

37. Roelofs PD, Deyo RA, Koes BW, Scholten RJ, van Tulder MW. Nonsteroidal anti-inflammatory drugs for low back pain: an updated Cochrane review. Spine. 2008;33(16):1766-74.

38. Rothoerl RD, Woertgen C, Holzschuh M, Rueschoff J, Brawanski A. Is there a clinical correlate to the histologic evidence of inflammation in herniated lumbar disc tissue? Spine (Phila Pa 1976). 1998;23(11):1197-200 discussion 1200-1191.

39. Sieper J, van der Heijde D, Landewe R, et al. New criteria for inflammatory back pain in patients with chronic back pain: a real patient exercise by experts from the assessment of SpondyloArthritis international society (ASAS). Ann Rheum Dis. 2009;68(6):784-8.

40. Smart KM, Blake C, Staines A, Doody C. Clinical indicators of 'nociceptive', 'peripheral neuropathic' and 'central' mechanisms of musculoskeletal pain. A Delphi survey of expert clinicians. Man Ther. 2010;15(1):80-7.

41. Tawa N, Rhoda A, Diener I. Accuracy of clinical neurological examination in diagnosing lumbo-sacral radiculopathy: a systematic literature review. BMC Musculoskelet Disord. 2017;18(1):93.

42. Underwood MR, Dawes P. Inflammatory back pain in primary care. Br J Rheumatol. 1995;34(11):1074-7.

43. van den Berg R, Jongbloed EM, de Schepper EIT, et al. The association between pro-inflammatory biomarkers and nonspecific low back pain: a systematic review. Spine J. 2018;18(11):2140-51.

44. Verhagen AP, Downie A, Maher CG, Koes BW. Most red flags for malignancy in low back pain guidelines lack empirical support: a systematic review. Pain. 2017;158(10):1860-8.

45. Virri J, Grönblad M, Seitsalo S, et al. Comparison of the prevalence of inflammatory cells in subtypes of disc herniations and associations with straight leg raising. Spine. 2001;26(21):2311-5.

46. Vittinghoff $E, M c C u l l o c h ~ C E$. Relaxing the rule of ten events per variable in logistic and cox regression. Am J Epidemiol. 2007;165(6):710-8.

47. Waddell G, McCulloch J, Kummel E, Venner R. Nonorganic physical signs in low back pain. Spine. 1980;5(2):117-25.

48. Walker BF, Williamson OD. Mechanical or inflammatory low back pain. What are the potential signs and symptoms? Man Ther. 2009;14(3):314-20.

49. Weisman MH. Inflammatory back pain: the United States perspective. Rheum Dis Clin N Am. 2012;38(3):501-12.

50. Westman A, Linton SJ, Ohrvik J, Wahlen P, Leppert J. Do psychosocial factors predict disability and health at a 3-year follow-up for patients with non-acute musculoskeletal pain? A validation of the Orebro musculoskeletal pain screening questionnaire. Eur J Pain. 2008;12(5):641-9.

\section{Publisher's Note}

Springer Nature remains neutral with regard to jurisdictional claims in published maps and institutional affiliations. 